\title{
Should Exercise Be Prescribed Differently Between Women and Men? An Emphasis on Women Diagnosed With Parkinson's Disease
}

\author{
Brandon R. Rigby* and Ronald W. Davis \\ Department of Kinesiology, Texas Woman's University, Denton, TX, United States
}

Keywords: aerobic, female, flexibility, functional abilities, neurodegenerative, resistance

\section{INTRODUCTION}

Parkinson's disease (PD) is a neurodegenerative disease caused by a reduction in dopaminergic neurons in the substantia nigra (Dexter and Jenner, 2013). Individuals can exhibit muscle tremors, rigidity, and bradykinesia, leading to posture and gait abnormalities (Dexter and Jenner, 2013). Although the incidence ratio of males to females is $\sim 1.46$ (Taylor et al., 2007), the prevalence of PD among men is doubled when compared to women (Elbaz et al., 2002). A lower mortality rate has traditionally been associated with PD in women due to the overall longer life expectancy when compared to men in the general population (Xu et al., 2014; Pinter et al., 2015). However, a diagnosis of $\mathrm{PD}$ was found to be associated with a two-fold increased risk for all-cause mortality in a recent study with 396 older women (Winter et al., 2016). This value is similar to that reported among older men (Xu et al., 2014).

Males may have a greater predisposition to develop PD (Gillies et al., 2014). This bias may be due to the molecular pathology of PD. Gene expression profiles in dopaminergic neurons are sexspecific, and the survivability of these neurons are dependent on molecular pathways that are very different in men and women (Gillies et al., 2014). In healthy brain tissue, genes involved in signal transduction and neuronal growth are up-regulated more in women (Cantuti-Castelvetri et al., 2007). In men, genes with specific mutations (e.g., $\alpha$-synuclein, PINK-1) that may contribute to the pathogenesis of PD are upregulated more often (Simunovic et al., 2010). A downregulation of genes that provide for oxidative phosphorylation, and synaptic and nerve impulse transmission, is also more prevalent in older males (Simunovic et al., 2010). Therefore, women are thought to have greater protection from PD when compared to men, which may also be due to estrogen concentrations (Gillies et al., 2014).

Estrogen influences dopamine synthesis and release while inhibiting dopamine uptake (Shulman, 2007). The higher concentrations of estrogen are a possible reason for the more benign phenotype in women when compared to men, particularly before a course of medication has begun (Haaxma et al., 2007; Miller and Cronin-Golomb, 2011; Cereda et al., 2013). Estrogen may play a role in preventing toxins from possibly degrading neurons in the substantia nigra (Shulman, 2007). Exogenous or endogenous estrogen administration may therefore play a crucial role in the pathogenesis of PD (Lv et al., 2017). There are several factors, including medicinal options, surgical interventions, dietary strategies, and lifestyle habits that may alter estrogen levels in women with PD. Oral contraceptive (OC) use may increase the risk of PD among women (Nicoletti et al., 2011), with a $20 \%$ increased risk of developing PD for every five years of OC use (Simon et al., 2009). However, the use of OCs has been also been shown to be inversely associated with PD risk (Greene et al., 2014), with continuous use for more than 10 years determined to even be a protective mechanism against developing PD (Liu et al., 2014). Following an ovariectomy, a 
decrease in the concentration of estrogen receptor- $\alpha$ and an increase in angiotensin, NADPH-oxidase activity, and the expression of neuroinflammatory markers was observed in the substantia nigra of menopausal rats (Rodriguez-Perez et al., 2015). Smoking may increase levels of estrogen and serum sex hormone-binding globulin, and may also be protective against $\mathrm{PD}$, as an inverse correlation between smoking and PD risk has been shown (Ritz et al., 2007; Breckenridge et al., 2016). Proper intake of vitamin D may increase glial derived neurotrophic factor (Smith et al., 2006) and reduce activated microglial cells (Kim et al., 2006), therefore acting as a neuroprotectant with estrogen and reducing inflammation. The protective effect of estrogen is not always evident, particularly in women who report a more rapid onset of motor symptoms upon diagnosis (Sato et al., 2006; Colombo et al., 2015; Bjornestad et al., 2016).

With regard to motor symptoms, women typically present more with tremors and bradykinesia, but not rigidity, when compared to men (Haaxma et al., 2007; Martinez-Martin et al., 2012). Non-motor symptoms, such as constipation, restless legs, pain, nervousness, anxiety, and sadness, are more prevalent in women (Martinez-Martin et al., 2012; Solla et al., 2012; Picillo et al., 2013; Szewczyk-Krolikowski et al., 2014). A reduction in visuospatial cognition also occurs more frequently in women (Miller and Cronin-Golomb, 2011).

To treat the motor and non-motor symptoms of PD, individuals are often presented with a variety of options. Medications and surgical procedures are available but are often unsuccessful at treating all symptoms of $\mathrm{PD}$, can be expensive and invasive, and may lead to unwanted side effects (Bloem et al., 2004). Exercise may therefore be an inexpensive and complementary option to other interventions to treat symptoms of $\mathrm{PD}$. Performing regular exercise may improve numerous functional outcome measures and quality-of-life, particularly in higher-functioning individuals diagnosed with neurodegenerative diseases, including PD, multiple sclerosis, and dementia (Dodd et al., 2011; Brienesse and Emerson, 2013; Morley et al., 2015).

\section{EXERCISE AND PARKINSON'S DISEASE}

Gait speed is slower in older women, possibly due to observed increases in muscle strength and standing balance ability in men (Bohannon, 1997). When compared to men with PD, women with PD exhibit increased cadence and decreased stride length and frequency (Kokko et al., 1997; Pedersen et al., 1997). To improve gait, motor performance, and quality-of-life, aerobic exercise on a motorized treadmill may be effective intervention for those with PD (Herman et al., 2007). Treadmill exercise can improve motor function, stride and swing time variability, and gait speed in adults with mild to moderate PD (Herman et al., 2007). This in turn may allow for greater mobility during activities of daily living (ADLs) and a reduced incidence of falls (Cakit et al., 2007; Herman et al., 2007). Performance during ADLs may be enhanced more with the use of external sensory cues during exercise (Cassimatis et al., 2016). These auditory, visual, or tactile cues bypass the basal ganglia using alternative pathways (e.g., cortical, parietopremotor) when processed, thus creating an additive improvement in ADL performance (Kones, 2010).

Resistance and flexibility exercises are also recommended for individuals diagnosed with PD. Resistance exercise training can improve muscle strength, muscular endurance, fat-free mass, balance and mobility, and walking economy in adults with PD (Brienesse and Emerson, 2013). When assessing lower limb strength, Pääsuke et al. (2002) found that reaction times and maximum isometric force values were different between legs in women with PD. This may be due to the postural and balance impairments that are prevalent with a diagnosis of PD. Using regression analysis, Schenkman et al. (1998) found a greater correlation between women with PD and poor spinal flexibility and balance when compared to men with PD.

Alternative modalities of exercise, including Nordic walking (Cugusi et al., 2017), tai chi (Hackney and Earhart, 2008), and tango dancing (Hackney et al., 2007), may also elicit improvements in balance and mobility in those with PD. Virtual reality (VR) is a newer technology that may be integrated into a rehabilitative program for those with PD. By allowing for repetitive movement that targets both motor and cognitive performance, VR may allow for the learning or re-learning of motor strategies that have been lost due to the progression of PD (Goble et al., 2014).

\section{EXERCISE PRESCRIPTION RECOMMENDATIONS}

Traditional aerobic and resistance exercise should be prescribed differently to women diagnosed with PD due to the possible inherent sex differences in this population. Current exercise guidelines for adults with PD and proposed guidelines for women with PD are found in Table 1. As PD is a risk factor for osteoporosis, appropriate aerobic modalities should be chosen for women with PD. Short, supervised walks on a level surface with occasional turns (e.g., an athletic track), to add variation to the direction of loads, may be the best aerobic exercise modality that can be prescribed to women with PD. If not ambulatory, leg ergometry may be a suitable option, with a focus on resistance rather than speed. Intensity should be prescribed using $\mathrm{VO}_{2}$ reserve (if available) or rate of perceived exertion (RPE). Prescribing intensity using heart rate responses should not be recommended, as many individuals with PD exhibit autonomic nervous system (ANS) dysfunction (e.g., sympathetic denervation) and are prescribed medications that can interfere with heart rate responses and heart rate variability (Ziemssen and Reichmann, 2010; Moore et al., 2016). This ANS dysfunction is thought to contribute to fatigue in those with PD (Nakamura et al., 2011). Session duration and frequency, particularly at the start of an exercise program, should therefore be limited.

Squats using only body weight or with additional weight may be the most appropriate resistance exercise modality for women with PD. Squats are closed-chain kinetic exercises, which may 
TABLE 1 | Exercise guidelines for adults diagnosed with Parkinson's disease.

\begin{tabular}{|c|c|c|c|}
\hline Modality & Frequency & Intensity & Duration \\
\hline \multicolumn{4}{|c|}{ CURRENT GUIDELINES FOR ADULTS WITH PD } \\
\hline \multicolumn{4}{|l|}{ Aerobic } \\
\hline $\begin{array}{l}\text { Leg and arm ergometry } \\
\text { Walking } \\
\text { Cycling }\end{array}$ & 3-4 days/week & $\begin{array}{l}30-60 \% \mathrm{VO}_{2} \mathrm{R} \\
30-60 \% \mathrm{HRR} \\
55-75 \% \mathrm{HR}_{\max } \\
\text { RPE 9-13 }\end{array}$ & $\begin{array}{l}30-60 \mathrm{~min} / \text { session } \\
\text { Up to } 6 \text { sessions/day (for walking only) }\end{array}$ \\
\hline $\begin{array}{l}\text { Machines and free weights } \\
\text { Closed-chain kinetic exercises }\end{array}$ & 3-4 days/week & $40-80 \% 1 \mathrm{RM}$ & $1-3$ sets of $8-12$ reps \\
\hline \multicolumn{4}{|l|}{ Flexibility } \\
\hline Static stretching & 3 days/week & $\begin{array}{l}\text { Joints at full } \\
\text { flexion/extension }\end{array}$ & Up to $30 \mathrm{sec} / \mathrm{stretch}$ \\
\hline \multicolumn{4}{|c|}{ PROPOSED GUIDELINES FOR WOMEN WITH PD } \\
\hline \multicolumn{4}{|l|}{ Resistance } \\
\hline $\begin{array}{l}\text { Squats } \\
\text { Closed-chain kinetic exercises } \\
\text { Machines }\end{array}$ & $\begin{array}{l}\text { Begin: } 1 \text { day/week } \\
\text { Progress to: } 2-3 \text { days/week }\end{array}$ & $\begin{array}{l}\text { Against body weight, up to } \\
80 \% 1 \mathrm{RM}\end{array}$ & $1-3$ sets of $8-12$ reps \\
\hline \multicolumn{4}{|l|}{ Flexibility } \\
\hline Static and dynamic stretching & 3-5 days/week & $\begin{array}{l}\text { Joints at full } \\
\text { flexion/extension }\end{array}$ & Up to $30 \mathrm{sec} / \mathrm{stretch}$ \\
\hline
\end{tabular}

Current guidelines adapted from Moore et al. (2016) and Jacobs (2018). Establishing a conservative $5 R M$ or $10 R M$ may be needed for some clients. VO $\mathrm{O}_{2} \mathrm{R}=\mathrm{VO}_{2}$ reserve; $H R_{\text {max }}=$ maximum heart rate; $H R R=$ heart rate reserve; $R P E=$ rate of perceived exertion; $1 R M=1$ repetition maximum.

be a more suitable exercise due to the abnormal coordination between limbs caused by a greater prevalence of tremors at rest in women with PD (Ehrman et al., 2013). The strength of the quadriceps, the prime movers during the upward phase of a squat, is correlated with functional abilities and performance during ADLs (Moore et al., 2016). Targeting the quadriceps musculature during exercise is beneficial because the extensors typically exhibit more muscle weakness than the flexors, and there is evidence that proximal muscles are weaker than distal muscles in those with PD (Inkster et al., 2003; Cano-de-la-Cuerda et al., 2010). The induced compression during the exercise may also improve bone mineral density (BMD) at the hip. Machine weights may be an added supplement to resistance training once increases in volume and frequency can be tolerated.

Flexibility training needs to be incorporated into an exercise program for those with PD. A combination of stretching and resistance exercise can improve muscle strength and gait speed in this population (Shulman et al., 2013). As women with PD typically exhibit more frequent episodes of bradykinesia, increasing the strength of skeletal muscles (particularly lower body) and gait parameters is crucial (Haaxma et al., 2007).

\section{CONCLUSIONS}

The Office of Research on Women's Health (ORWH) within the National Institutes of Health (NIH) has called for research scientists to consider sex when designing study protocols to allow for both men and women to receive the full benefit of medical research (National Institutes of Health, 2017). Exercise is an effective intervention that can elicit functional changes in adults with PD. Women with PD should follow an exercise prescription that somewhat deviates from the current exercise guidelines, which are not categorized according to sex. This deviation is due in part to the differences observed with the timing of PD onset and progression, primary symptoms, and hormonal changes that are exhibited in women with PD. A comparison of the physiological effects of exercise training between men and women with PD needs to be further investigated to allow clinicians and health practitioners to correctly prescribe exercise as a long-term option to treat the symptoms of PD.

\section{AUTHOR CONTRIBUTIONS}

All authors listed have made a substantial, direct and intellectual contribution to the work, and approved it for publication.

\section{ACKNOWLEDGMENTS}

This article was published with support from the Texas Woman's University Libraries' Open Access Fund. 


\section{REFERENCES}

Bjornestad, A., Forsaa, E. B., Pedersen, K. F., Tysnes, O. B., Larsen, J. P., and Alves, G. (2016). Risk and course of motor complications in a population-based incident Parkinson's disease cohort. Parkinsonism Relat. Disord. 22, 48-53. doi: 10.1016/j.parkreldis.2015.11.007

Bloem, B. R., Hausdorff, J. M., Visser, J. E., and Giladi, N. (2004). Falls and freezing of gait in Parkinson's disease: a review of two interconnected, episodic phenomena. Mov. Disord. 19, 871-884. doi: 10.1002/mds.20115

Bohannon, R. W. (1997). Reference values for extremity muscle strength obtained by hand-held dynamometry from adults aged 20 to 79 years. Arch. Phys. Med. Rehabil. 78, 26-32. doi: 10.1016/S0003-9993(97)90005-8

Breckenridge, C. B., Berry, C., Chang, E. T., Sielken, R. L., and Mandel, J. S. (2016). Associated between Parkinson's disease and cigarette smoking, rural living, well-water consumption, farming and pesticide use: systematic review and analysis. PLOS ONE 11:e0151841. doi: 10.1371/journal.pone.01 51841

Brienesse, L. A., and Emerson, M. N. (2013). Effects of resistance training for people with Parkinson's disease: a systematic review. J. Am. Med. Dir. Assoc. 14, 236-241. doi: 10.1016/j.jamda.2012.11.012

Cakit, B. D., Saracoglu, M., Genc, H., Erdem, H. R., and Inan, L. (2007). The effects of incremental speed-dependent treadmill training on postural instability and fear of falling in Parkinson's disease. Clin. Rehabil. 21, 698-705. doi: $10.1177 / 0269215507077269$

Cano-de-la-Cuerda, R., Pérez-de-Heredia, M., Miangolarra-Page, J. C., MuñozHellín, E., and Fernández-de-Las-Peñas, C. (2010). Is there muscular weakness in Parkinson's disease? Am. J. Phys. Med. Rehabil. 89, 70-76. doi: 10.1097/PHM.0b013e3181a9ed9b

Cantuti-Castelvetri, I., Keller-McGandy, C., Bouzou, B., Asteris, G., Clark, T. W., Frosch, M. P., et al. (2007). Effects of gender on nigral gene expression and parkinson disease. Neurobiol. Dis. 26, 606-614. doi: 10.1016/j.nbd.2007. 02.009

Cassimatis, C., Liu, K. P., Fahey, P., and Bissett, M. (2016). The effectiveness of external sensory cues in improving functional performance in individuals with Parkinson's disease: a systematic review with meta-analysis. Int. J. Rehabil. Res. 39, 211-218. doi: 10.1097/MRR.0000000000000171

Cereda, E., Barichella, M., Cassani, E., Caccialanza, R., and Pezzoli, G. (2013). Reproductive factors and clinical features of Parkinson's disease. Parkinsonism Relat. Disord. 19, 1094-1099. doi: 10.1016/j.parkreldis.2013.07.020

Colombo, D., Abbruzzese, G., Antonini, A., Barone, P., Bellia, G., Franconi, F., et al. (2015). The "Gender Factor" in wearing-off among patients with Parkinson's disease: a post hoc analysis of DEEP study. Sci. World J. 2015:787451. doi: 10.1155/2015/787451

Cugusi, L., Manca, A., Dragone, D., Deriu, F., Solla, P., Secci, C., et al. (2017). Nordic walking for the management of people with Parkinson disease: a systematic review. PM R 9, 1157-1166. doi: 10.1016/j.pmrj.2017.06.021

Dexter, D. T., and Jenner, P. (2013). Parkinson disease: from pathology to molecular disease mechanisms. Free Radic. Biol. Med. 62, 132-144. doi: 10.1016/j.freeradbiomed.2013.01.018

Dodd, K. J., Taylor, N. F., Shields, N., Prasad, D., McDonald, E., and Gillon, A. (2011). Progressive resistance training did not improve walking but can improve muscle performance, quality of life and fatigue in adults with multiple sclerosis: a randomized controlled trial. Mult. Scler. 17, 1362-1374. doi: 10.1177/1352458511409084

Ehrman, J. K., Gordon, P. M., Visich, P. S., and Keteyian, S. J. (2013). Clinical Exercise Physiology. Champaign, IL: Human Kinetics.

Elbaz, A., Bower, J. H., Maraganore, D. M., McDonnell, S. K., Peterson, B. J., Ahlskog, J. E., et al. (2002). Risk tables for parkinsonism and Parkinson's disease. J. Clin. Epidemiol. 55, 25-31. doi: 10.1016/S0895-4356(01)00425-5

Gillies, G. E., Pienaar, I. S., Vohra, S., and Qamhawi, Z. (2014). Sex differences in Parkinson's disease. Front. Neuroendocrinol. 35, 370-384. doi: 10.1016/j.yfrne.2014.02.002

Goble, D. J., Cone, B. L., and Fling, B. W. (2014). Using the Wii Fit as a tool for balance assessment and neurorehabilitation: the first half decade of "Wii-search." J. Neuroeng. Rehabil. 11:12. doi: 10.1186/1743-0003-11-12

Greene, N., Lassen, C. F., Rugbjerg, K., and Ritz, B. (2014). Reproductive factors and Parkinson's disease risk in Danish women. Eur. J. Neurol. 21, 1168-1177. doi: $10.1111 /$ ene. 12450
Haaxma, C. A., Bloem, B. R., Borm, G. F., Oyen, W. J., Leenders, K. L., Eshuis, S., et al. (2007). Gender differences in Parkinson's disease. J. Neurol. Neurosurg. Psychiatry 78, 819-824. doi: 10.1136/jnnp.2006.103788

Hackney, M. E., and Earhart, G. M. (2008). Tai Chi improves balance and mobility in people with Parkinson disease. Gait Posture 28, 456-460. doi: 10.1016/j.gaitpost.2008.02.005

Hackney, M. E., Kantorovich, S., Levin, R., and Earhart, G. M. (2007). Effects of tango on functional mobility in Parkinson's disease: a preliminary study. J. Neurol. Phys. Ther. 31, 173-179. doi: 10.1097/NPT.0b013e31815 ce78b

Herman, T., Giladi, N., Gruendlinger, L., and Hausdorff, J. M. (2007). Six weeks of intensive treadmill training improves gait and quality of life in patients with Parkinson's disease: a pilot study. Arch. Phys. Med. Rehabil. 88, 1154-1158. doi: 10.1016/j.apmr.2007.05.015

Inkster, L. M., Eng, J. J., MacIntyre, D. L., and Stoessl, A. J. (2003). Leg muscle strength is reduced in Parkinson's disease and relates to the ability to rise from a chair. Mov. Disord. 18, 157-162. doi: 10.1002/mds.10299

Jacobs, P. L. (2018). NSCA's Essentials of Training Special Populations. Champaign, IL: Human Kinetics.

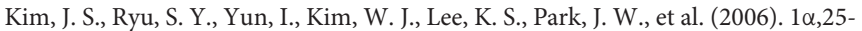
dihydroxyvitamin $\mathrm{D}(3)$ protects dopaminergic neurons in rodent models of Parkinson's disease through inhibition of microglial activation. J. Clin. Neurol. 2, 252-257. doi: 10.3988/jen.2006.2.4.252

Kokko, S. M., Paltamaa, J., Ahola, E., and Mälkiä, E. (1997). The assessment of functional ability in patients with Parkinson's disease: the PLM-test and three clinical tests. Physiother. Res. Int. 2, 29-45. doi: 10.1002/pri.88

Kones, R. (2010). Parkinson's disease: mitochondrial molecular pathology, inflammation, statins, and therapeutic neuroprotective nutrition. Nutr. Clin. Pract. 25, 371-389. doi: 10.1177/0884533610373932

Liu, R., Baird, D., Park, Y., Freedman, N. D., Huang, X., Hollenbeck, A., et al. (2014). Female reproductive factors, menopausal hormone use, and Parkinson's disease. Mov. Disord. 29, 889-896. doi: 10.1002/mds.25771

Lv, M., Zhang, Y., Chen, G. C., Li, G., Rui, Y., Qin, L., et al. (2017). Reproductive factors and risk of Parkinson's disease in women: a meta-analysis of observational studies. Behav. Brain Res. 335, 103-110. doi: 10.1016/j.bbr.2017.07.025

Martinez-Martin, P., Falup Pecurariu, C., Odin, P., van Hilten, J. J., Antonini, A., Rojo-Abuin, J. M., et al. (2012). Gender-related differences in the burden of non-motor symptoms in Parkinson's disease. J. Neurol. 259, 1639-1647. doi: 10.1007/s00415-011-6392-3

Miller, I. N., and Cronin-Golomb, A. (2011). Gender differences in Parkinson's disease: clinical characteristics and cognition. Mov. Disord. 25, 2695-2703. doi: $10.1002 / \mathrm{mds} .23388$

Moore, G. E., Durstine, J. L., and Painter, P. L. (2016). ACSM's Exercise Management for Persons with Chronic Diseases and Disabilities. Champaign, IL: Human Kinetics.

Morley, J. E., Morris, J. C., Berg-Weger, M., Borson, S., Carpenter, B. D., Del Campo, N., et al. (2015). Brain health: the importance of recognizing cognitive impairment: an IAGG consensus conference. J. Am. Med. Dir. Assoc. 16, 731-739. doi: 10.1016/j.jamda.2015.06.017

Nakamura, T., Hirayama, M., Hara, T., Hama, T., Watanabe, H., and Sobue, G. (2011). Does cardiovascular autonomic dysfunction contribute to fatigue in Parkinson's disease? Mov. Disord. 26, 1869-1874. doi: 10.1002/mds. 23744

National Institutes of Health. (2017). "Sex/Gender." Available online at: https:// orwh.od.nih.gov/research/sex-gender/ (Accessed Nov 19, 2017).

Nicoletti, A., Nicoletti, G., Arabia, G., Annesi, G., De Mari, M., Lamberti, P., et al. (2011). Reproductive factors and Parkinson's disease: a multicenter case-control study. Mov. Disord. 26, 2563-2566. doi: 10.1002/mds.23951

Pääsuke, M., Mottus, K., Ereline, J., Gapeyeva, H., and Taba, P. (2002). Lower limb performance in older female patients with Parkinson's disease. Aging Clin. Exp. Res. 14, 185-191. doi: 10.1007/BF03324434

Pedersen, S. W., Oberg, B., Larsson, L. E., and Lindval, B. (1997). Gait analysis, isokinetic muscle strength measurement in patients with Parkinson's disease. Scand. J. Rehabil. Med. 29, 67-74.

Picillo, M., Amboni, M., Erro, R., Longo, K., Vitale, C., Moccia, M., et al. (2013). Gender differences in non-motor symptoms in early, drug naïve Parkinson's disease. J. Neurol. 260, 2849-2855. doi: 10.1007/s00415-013-7085-x 
Pinter, B., Diem-Zangerl, A., Wenning, G. K., Scherfler, C., Oberaigner, W., Seppi, K., et al. (2015). Mortality in Parkinson's disease: a 38-year follow-up study. Mov. Disord. 30, 266-269. doi: 10.1002/mds.26060

Ritz, B., Ascherio, A., Checkoway, H., Marder, K. S., Nelson, L. M., Rocca, W. A., et al. (2007). Pooled analysis of tobacco use and risk of Parkinson disease. Arch. Neurol. 64, 990-997. doi: 10.1001/archneur.64.7.990

Rodriguez-Perez, A. I., Borrajo, A., Valenzuela, R., Lanciego, J. L., and LabandeiraGarcia, J. L. (2015). Critical period for dopaminergic neuroprotection by hormonal replacement in menopausal rats. Neurobiol. Aging 36, 1194-1208. doi: 10.1016/j.neurobiolaging.2014.10.028

Sato, K., Hatano, T., Yamashiro, K., Kagohashi, M., Nishioka, K., Izawa, N., et al. (2006). Prognosis of Parkinson's disease: time to stage III, IV, V, and to motor fluctuations. Mov. Disord. 21, 1384-1395. doi: 10.1002/mds.20993

Schenkman, M., Cutson, T. M., Kuchibhatla, M., Chandler, J., Pieper, C. F., Ray, L., et al. (1998). Exercise to improve spinal flexibility and function for people with Parkinson's disease: a randomized, controlled trial. J. Am. Geriatr. Soc. 46, 1207-1216. doi: 10.1111/j.1532-5415.1998.tb04535.x

Shulman, L. M. (2007). Gender differences in Parkinson's disease. Gend. Med. 4, 8-18. doi: 10.1016/S1550-8579(07)80003-9

Shulman, L. M., Katzel, L. I., Ivey, F. M., Sorkin, J. D., Favors, K., and Anderson, K. E. (2013). Randomized clinical trial of 3 types of physical exercise for patients with Parkinson's disease. JAMA Neurol. 70, 183-190. doi: 10.1001/jamaneurol.2013.646

Simon, K. C., Chen, H., Gao, X., Schwarzschild, M. A., and Ascherio, A. (2009). Reproductive factors, exogenous estrogen use, and risk of Parkinson's disease. Mov. Disord. 24, 1359-1365. doi: 10.1002/mds.22619

Simunovic, F., Yi, M., Wang, Y., Stephens, R., and Sonntag, K. C. (2010). Evidence for gender-specific transcriptional profiles of nigral dopamine neurons in Parkinson disease. PLoS ONE 5:e8856. doi: 10.1371/journal.pone.0008856

Smith, M. P., Fletcher-Turner, A., Yurek, D. M., and Cass, W. A. (2006). Calcitriol protection against dopamine loss induced by intracerebroventricular administration of 6-hydroxydopamine. Neurochem. Res. 31, 533-539. doi: 10.1007/s11064-006-9048-4
Solla, P., Cannas, A., Ibba, F. C., Loi, F., Corona, M., Orofino, G., et al. (2012). Gender differences in motor and non-motor symptoms among Sardinian patients with Parkinson's disease. J. Neurol. Sci. 323, 33-39. doi: 10.1016/j.jns.2012.07.026

Szewczyk-Krolikowski, K., Tomlinson, P., Nithi, K., Wade-Martinis, R., Talbot, K., Ben-Shlomo, Y., et al. (2014). The influence of age and gender on motor and non-motor features of early Parkinson's disease: initial findings from the Oxford Parkinson Disease Center (OPDC) discovery cohort. Parkinsonism Relat. Disord. 20, 99-105. doi: 10.1016/j.parkreldis.2013. 09.025

Taylor, K. S., Cook, J. A., and Counsell, C. E. (2007). Heterogeneity in male to female risk for Parkinson's disease. J. Neurol. Neurosurg. Psychiatry 78, 905-906. doi: 10.1136/jnnp.2006.104695

Winter, A. C., Rist, P. M., Buring, J. E., and Kurth, T. (2016). Prospective comorbidity-matched study of Parkinson's disease and risk of mortality among women. BMJ Open 6:e011888. doi: 10.1136/bmjopen-2016-0 11888

Xu, J., Gong, D. D., Man, C. F., and Fan, Y. (2014). Parkinson's disease and risk of mortality: meta-analysis and systematic review. Acta. Neurol. Scand. 129, 71-79. doi: 10.1111/ane.12201

Ziemssen, T., and Reichmann, H. (2010). Cardiovascular autonomic dysfunction in Parkinson's disease. J. Neurol. Sci. 289, 74-80. doi: 10.1016/j.jns.2009.08.031

Conflict of Interest Statement: The authors declare that the research was conducted in the absence of any commercial or financial relationships that could be construed as a potential conflict of interest.

Copyright (C) 2018 Rigby and Davis. This is an open-access article distributed under the terms of the Creative Commons Attribution License (CC BY). The use, distribution or reproduction in other forums is permitted, provided the original author(s) and the copyright owner(s) are credited and that the original publication in this journal is cited, in accordance with accepted academic practice. No use, distribution or reproduction is permitted which does not comply with these terms. 